\title{
PERANCANGAN SISTEM PENGONTROLAN KIPAS ANGIN BERBASIS MIKROKONTROLLER
}

\author{
Ahmad Hanafie ${ }^{1}$, Sriwati $^{2}$, Muliawati ${ }^{3}$, Rini Rusmaini Usman ${ }^{4}$ \\ 1. Program Studi Teknik Industri, Fakultas Teknik, Universitas Islam Makassar \\ 2, Program Studi Teknik Elektro, Fakultas Teknik, Universitas Islam Makassar \\ ${ }^{3,4}$ Program Studi Teknik Informatika, Fakultas Teknik, Universitas Islam Makassar \\ Email:ahmadhanafie.dty@uim-makassar.ac.id, sriwati.dty@uim-makassar.ac.id, \\ Muliawatiteknik29@gmail.com
}

\begin{abstract}
ABSTRAK
Saat ini perkembangan teknologi begitu maju dan menyajikan berbagai kelebihan-kelebihan yang menarik dan luar biasa. Teknologi yang berkembang saat ini menghasilkan berbagai macam alat elektronik yang memudahkan manusia menyelesaikan masalah dalam kehidupan sehari-hari. Penelitian ini bertujuan untuk mengetahui cara merancang suatu sistem dan bagaimana kinerja sensor suhu LM35 serta PIR. Metode penelitian dan pengembangan (RnD) dengan Arduino UNO sebagai pusat kendali rangkaian. Hasil dari penelitian ini yaitu terbangunnya sebuah sistem pengontrolan kipas angin berbasis mikrokontroller yang mana kipas akan berputar apabila sensor PIR mendeteksi bayangan serta sensor suhu LM35 membaca suhu sekitar $\geq 25$ sampai $\geq 30$ derajat kipas menyala dengan kecepatan rendah, Suhu sekitar $\geq 35$ derajat kipas menyala dengan kecepatan sedang, Suhu sekitar $\geq 40$ sampai $\geq 45$ derajat kipas menyala dengan kecepatan tinggi dan apabila sensor PIR tidak mendeteksi bayangan kipas akan berhenti berputar. Kesimpulan penelitian ini yaitu merancang sebuah sistem dan setelah dilakukan pengujian kinerja dari sensor suhu LM35 kurang stabil dalam membaca suhu ruangan dan kinerja dari sensor PIR kurang maksimal dalam mendeteksi bayangan.
\end{abstract}

Kata kunci: Kipas, Arduino, Sensor LM35, PIR

ABSTRACT

Currently the development of technology is so advanced and presents a variety of interesting and extraordinary advantages, the technology that is developing now produces various kinds of electronic devices that make it easy for humans to solve problems in their daily lives. This study aims to determine how to design a system and how the performance of LM35 and PIR temperature sensors. Research and development (RnD) methods with Arduino UNO as the series control center. The results of this study are the establishment of a microcontroller-based fan control system where the fan will rotate when the PIR sensor detects the shadow and the LM35 temperature sensor reads the temperature around $\geq 25$ to $\geq 30$ degrees the fan lights up at low speed, the ambient temperature of $\geq 35$ degrees the fan turns on with medium speed, Ambient temperature $\geq 40$ to $\geq 45$ degrees, the fan turns on at high speed and if the PIR sensor does not detect the shadow the fan will stop spinning. The conclusion of this research is to design a system and after testing the performance of the LM35 temperature sensor is less stable in reading room temperature and the performance of the PIR sensor is less than the maximum in detecting shadows.

Keywords: Fans, Arduino, LM35 Sensor, PIR 


\section{PENDAHULUAN}

Saat ini perkembangan teknologi begitu maju dan menyajikan berbagai kelebihan-kelebihan yang menarik dan luar biasa. Berkembangnya teknologi ini di dapat dari pengetahuan teknologi dan rasa ingin tahu manusia. Dengan adanya perkembangan teknologi ini dapat membantu mengatasi masalah yang dihadapi sehari-hari dengan memanfaatkan kecanggihannya yang mana memberikan berbagai macam kemudahan dalam penggunaannya. Teknologi yang berkembang saat ini menghasilkan berbagai macam alat elektronik yang memudahkan manusia menyelesaikan masalah dalam kehidupan sehari-hari.

Adapun salah satu masalah yang dihadapi yaitu tentang suhu di Indonesia, perubahan iklim yang dipicu naiknya suhu rata-rata atmosfir bumi seiring meningkatnya gas rumah kaca di atmosfir. Baik karena variabilitas alami atau sebagai hasil aktivitas manusia (IPCC, 2007). Suhu permukaan bumi mengalami kenaikan $0.85{ }^{\circ} \mathrm{C}$ ) selama periode 1880 2012 (IPCC, 2014). Sedangkan untuk wilayah Indonesia mengalami kenaikan suhu berkisar $0.8 \% 100$ tahun (Bappenas, 2014). hal ini yang dapat membuat manusia gampang gerah dan berkeringat.(Yadi Suryadi, 2017).

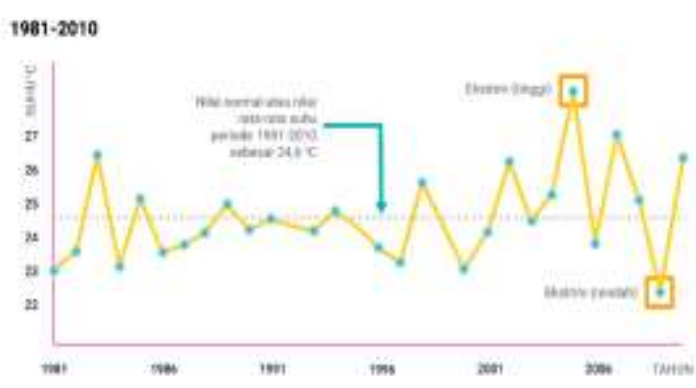

Gambar 1.grafik data suhu rata-rata tahunan selama 30 tahun (periode 1981-2010) (Sumber: http://ditjenppi)

Alat elektronik yang dapat digunakan untuk mengatasi masalah terhap suhu suatu ruangan contohnya, AC (Air Conditioner) yang mana merupakan alat elektronik yang berfungsi sebagai penyejuk di suatu ruangan yang memiliki suhu panas. Dipasaran AC banyak diminati karena sistem operasinya sudah otamatis dan ditambah dengan berbagai fitur-fitur sehingga pengoperasiannya mudah dilakukan. Namun harga AC cukup mahal sehingga tidak semua lapisan masyarakat dapat membelinya hanya kalangan menengah ke atas yang mampu memiliki. (Ari Wibowo, 2011) Karena hal tersebut kebanyakan masyarakat lebih memilih kipas angin sebagai penyejuk ruangan selain karena harga beli relative murah fungsinya pun hampir sama dengan AC.) Kipas angin juga lebih mudah ditemukan di pasaran, hanya saja pengoperasian kipas angin masih terbilang manual yang mana saat mengoperasikannya dengan menekan tombol power saat ingin menyalakan dan tombol kecepatan kipas.

Sebelumnya telah dibuat penelitian perancangan sistem kontrol kipas angin otomatis menggunakan sensor suhu LM35 berbasis mikrokontroller ATMega16 oleh (Lisinius Suryadi, 2015). Dengan adanya penelitian tersebut dapat menjadi basis penelitian dan pengembangan untuk penerapan berikutnya.

Maka dari itu kami berinisiatif membuat sebuah alat yang dirancang untuk membuat kipas angina berputar secara otomatis dengan menggunakan Arduino UNO sebagai pusat kendali dan sensor LM35 untuk membaca suhu ruangan serta Sensor PIR untuk mendeteksi bayangan.

\section{METODOLOGI PENELITIAN}

\section{Alat}

Alat yang digunakan dalam penelitian ini adalah Arduino UNO, Sensor PIR, Sensor LM35, LCD 16x2, Relay, LED, Laptop, Spidol, Bor, Tag, Penggaris, Cutter, Solder, PCB, Timah, Penghisap Tima, Adaptor, Kabel USB, Kabel Jumper.

\section{Bahan}

Bahan yang digunakan dalam penelitian ini adalah bahasa Pemrograman Bahasa C, Arduino IDE dan Sistem Operasi Windows 10.

\section{Metode Analisis}

Penelitian yang dilakukan merupakan jenis penelitian dan pengembangan atau Research and Development $(\mathrm{RnD})$ menggunakan metode ADDIE (Analysis Design Development Implement Evaluate). (Apriani Puji Lestari, 2015). Penelitian ini menggunakan metode pengumpulan data dengan melakukan observasi dan literatur. 
Rancang Flowchart Pengontrolan Kipas Angin

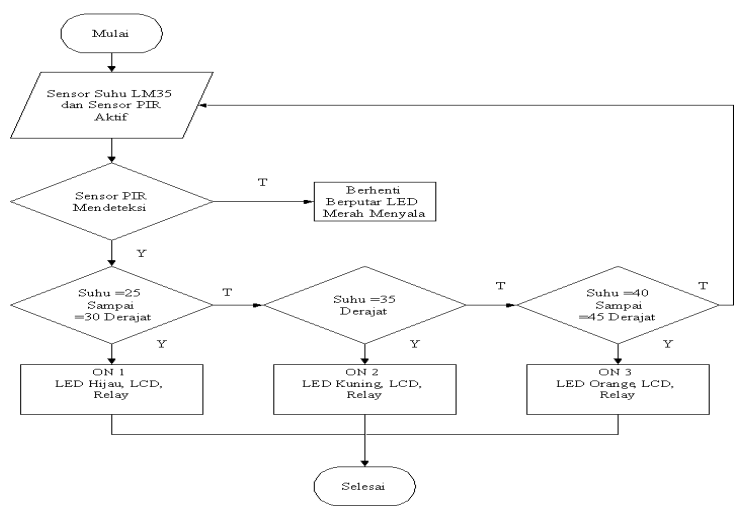

Gambar 3. Flowchart Pengontrolan Kipas Angin

\section{HASIL DAN PEMBAHASAN}

1. Perancangan Perangkat Keras

Perancangan perangkat keras yaitu tahap pertama menyediakan kipas angin duduk yang digunakan untuk memasang komponen arduino, sensor LM35, sensor PIR, LCD, LED, dan relay setelah itu tiap komponen di dalam kipas angin tersebut dihubungkan menggunakan kabel jumper, beberapa di solder dan kemudian di atur agar kelihatan rapih. Joni Parhan, (2018) juga telah melakukan penelitian mengenai rancangan bangun sistem kontrol kipas angin dan lampu otomatis di dalam ruangan berbasis Arduino uno R3 menggunakan multi sensor.

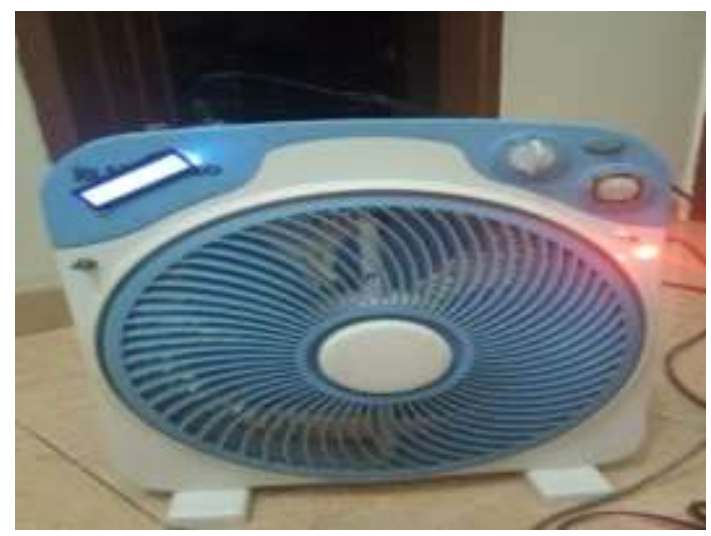

Gambar 4. Tampilan kipas Angin

Tahap berikutnya adalah menghubungkan semua komponen dengan Arduino uno dapat dilihat pada tabel berikut.
Tabel 2. Pengkoneksian LED, Relay, PIR dengan Arduino

\begin{tabular}{|c|c|c|c|}
\hline \multicolumn{4}{|c|}{ anduise di habungkas ke LED, velay dan sensor PIR } \\
\hline Arduao & LED & Relay & Seawor PIR \\
\hline Pin 6 & Anode $(+)$ led hijm & - & - \\
\hline pin 7 & Aoode (+) led kiaing & - & - \\
\hline Pin 8 & Anode (t) ied orange & - & - \\
\hline Pla 9 & Anodt $(+)$ led meah & - & - \\
\hline $\operatorname{Pin} 10$ & - & - & outpes \\
\hline GND & $\begin{array}{l}\text { Katode (-) led lijim, } \\
\text { kaning, mange dan } \\
\text { meal. }\end{array}$ & GND & GND \\
\hline 5N & - & $\mathrm{VOC}$ & VOC \\
\hline A] & - & $\mathrm{tN} 1$ & - \\
\hline A2 & - & $\mathrm{LN2}$ & - \\
\hline A3 & - & TN3 & - \\
\hline At & - & tN4 & - \\
\hline
\end{tabular}

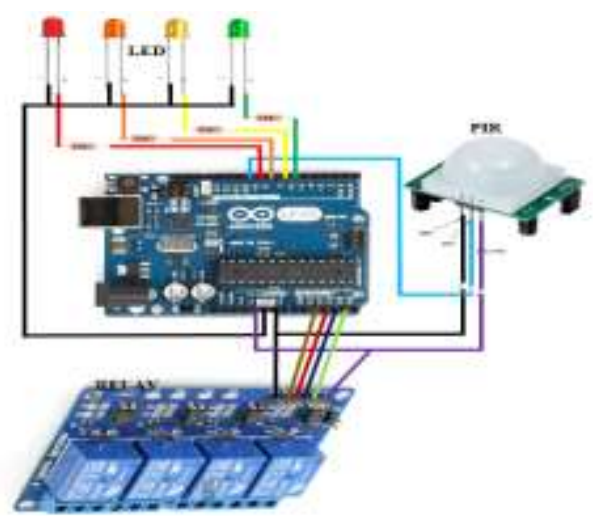

Gambar 5. Rangkaian LED, PIR, Relay dengan Arduino 
Tabel 3. Pengkoneksian LCD, LM35, Potensio dengan Arduino

\begin{tabular}{|c|c|c|c|}
\hline \multicolumn{4}{|c|}{ Arduies di habuagkanke LCD, seaser L.MDS daa poestió } \\
\hline Aruduits? & LCD & Senvor LU135 & Potensio \\
\hline $\operatorname{Pin} 2$ & D? & - & - \\
\hline Pin 3 & D6 & - & - \\
\hline Pin a & DS & - & - \\
\hline Pies: & D4 & - & - \\
\hline Pnt 11 & E & - & - \\
\hline Pin 12 & R5 & - & - \\
\hline GND & VSS dx RW: & GXD & GND \\
\hline $5 \mathrm{~V}$ & vec & $\mathrm{v} \propto \mathrm{C}$ & Inper \\
\hline A0 & - & Output & - \\
\hline- & VEE & - & Oarpes \\
\hline
\end{tabular}

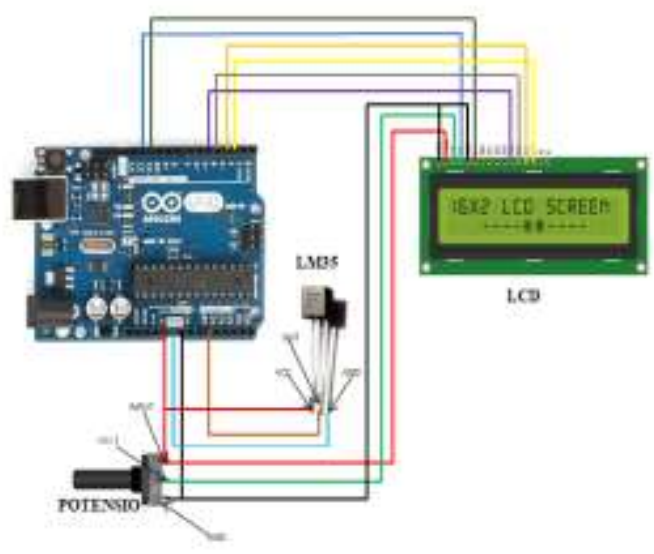

Gambar 6. Rangkaian LCD, LM35,Potensio dengan Arduino

\section{Perancangan Sistem}

Berikut merupakan indikator kerja dari perancangan sistem pengontrolan kipas angin berbasis mikrokontroller. Pembuatan sistem menggunakan sensor suhu LM35, sensor PIR, Arduino, LED, LCD dan relay ini melalui beberapa tahap yaitu dimulai dari mempersiapkan alat dan bahan yang digunakan seperti menyiapkan kipas angin duduk yang akan digunakan untuk meragkai komponen lain dan sebagai tempat uji coba alat.

\section{Hasil Pengujian Alat}

Dari 3 percobaan alat ini yang mana masingmasing memiliki data yang digunakan untuk membuktikan proses otomatisasinya. Data tersebut berupa sensor aktif atau sensor mendeteksi, kipas angin menyala maupun mati. Adapun hasil dari uji coba rangkaian yang telah dilakukan dapat dilihat pada tabel 4 dan 5 .

Tabel 4. Berdasarkan Setting Alat

\begin{tabular}{|c|c|c|c|}
\hline \multirow[b]{2}{*}{ No } & \multicolumn{2}{|c|}{ Bendasarkan Setting } & \multirow[t]{2}{*}{ Keternasal } \\
\hline & Penibarsan subse & $\begin{array}{c}\text { Kecepulah Kipas } \\
\text { angin }\end{array}$ & \\
\hline 1 & $\begin{array}{c}\text { Suhum } \geq 25-\geq 30 \\
\text { deraiat }\end{array}$ & ON 1 & 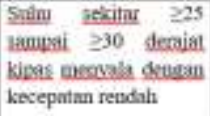 \\
\hline 2 & Sactar $>35$ derajat & ON 2 & 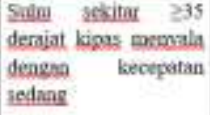 \\
\hline 3 & $\underset{\text { denajat }}{\text { Subu }} \geq 40-\geq 45$ & ON 3 & 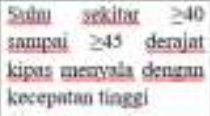 \\
\hline
\end{tabular}

Berdasarkan tabel 4, menujukkan ketika suhu $\geq 25$ $\geq 30$ derajat kipas berada pada ON 1 yaitu kipas menyala dengan kecepatan renda, ketika suhu $\geq 35$ derajat kipas berada pada ON 2 yaitu kipas menyala dengan kecepatan sedang dan ketika suhu $\geq 40-\geq 45$ derajat kipas berada pada ON 3 yaitu kipas menyala dengan kecepatan tinggi. Menurut (Ari Wibowo, 2011) berdasarkan setting alat, suhu $<20$ derajat Off , suhu 20-25 derajat On 1 dan suhu >25 derajat On 2.

Tabel 5. Tabel Hasil Pengujian

\begin{tabular}{|c|c|c|c|c|c|c|c|}
\hline \multirow{2}{*}{$\mathrm{N}_{0}$} & \multirow{2}{*}{$\begin{array}{l}\text { Sensor } \\
\text { LM35 }\end{array}$} & \multicolumn{2}{|c|}{ Sensot PIR } & \multicolumn{3}{|c|}{ Pembacsan Stahu } & \multirow{2}{*}{$\begin{array}{c}\text { LED } \\
\text { Memals }\end{array}$} \\
\hline & & Aktif & Mendeteksi & $\begin{array}{c}\text { Percobazn } \\
1\end{array}$ & $\begin{array}{c}\text { Percobaza } \\
2\end{array}$ & $\begin{array}{c}\text { Percobaan } \\
3\end{array}$ & \\
\hline 1 & Alktif & Aktif & $\begin{array}{c}\text { Tsdak } \\
\text { mendeteksi }\end{array}$ & $\begin{array}{l}48,83 \\
\text { derajzt }\end{array}$ & $\begin{array}{l}46,90 \\
\text { derzja: }\end{array}$ & $\begin{array}{l}35,16 \\
\text { derajat }\end{array}$ & Merah \\
\hline 2 & Altif & Aktif & Mendeteksi & $\begin{array}{l}27,35 \\
\text { derajat }\end{array}$ & $\begin{array}{l}31,25 \\
\text { derzja: }\end{array}$ & $\begin{array}{l}34,18 \\
\text { derajat }\end{array}$ & Hijw \\
\hline 3 & Aknt & Akthf & Mendeteksi & $\begin{array}{l}35,16 \\
\text { derajat }\end{array}$ & $\begin{array}{l}35,16 \\
\text { deraja: }\end{array}$ & $\begin{array}{l}35,65 \\
\text { derajat }\end{array}$ & Kuning \\
\hline 4 & Altrif & Aktrf & Mendeteksi & $\begin{array}{l}51,76 \\
\text { derajut }\end{array}$ & $\begin{array}{l}42,48 \\
\text { derajat }\end{array}$ & $\begin{array}{l}42,97 \\
\text { derajat }\end{array}$ & Orange \\
\hline
\end{tabular}

Berdasarkan tabel 5, hasil dari pengujian alat yang dilakukan percobaan sebanyak 3 kali tersebut dimulai saat kipas dalam mode ON, ketika sensor LM35 aktif, sensor PIR aktif namun tidak mendeteksi menampilkan suhu 48,83 derajat, 46,90 derajat, 35,16 derajat dan lampu LED yang menyala berwarna merah menandakan kipas tidak berputar. 
Menurut (Eka Desyantoro. 2015) pengujian sensor PIR dilakukan untuk menampilkan display ada manusia atau tidak. Jika terdeteksi adanya pergerakan manusia maka LCD akan menampilkan "H = 1", jika tidak terdeteksi pergerakan manusia maka LCD akan menampilkan " $\mathrm{H}=0$ ".

Ketika sensor LM35 aktif sensor PIR aktif dan mendeteksi menampilkan suhu 27,35 derajat, 31,25 derajat, 34,18 derajat dan lampu LED yang menyala berwarna hijau menandakan kipas berputar dengan kecepatan rendah, ketika sensor LM35 aktif, sensor PIR aktif dan mendeteksi menampilkan suhu 35,16 derajat, 35,16 derajat, 35,65 derajat dan lampu LED yang menyala berwarna kuning menandakan kipas berputar dengan kecepatan sedang dan ketika sensor LM35 aktif, sensor PIR aktif dan mendeteksi menampilkan suhu 51,76 derajat, 42,48 derajat, 42,97 derajat dan lampu LED yang menyala berwarna orange menandakan kipas berputar dengan kecepatan Tinggi. Menurut (Eka Desyantoro, 2015) perbandingan hasil pengujian sensor suhu LM35 dengan termometer menunjukan bahwa sensor mempunyai kesalahan $\pm 2^{0}$ celcius dari suhu yang yang ditunjukkan oleh termometer hal ini disebabkan karena LM35 sangat sensitive dengan keadaan sekita. Selain suhu angin juga dapat mempengaruhi hasil dari sensor suhu LM35.

\section{KESIMPULAN}

1. Perancangan dengan menggunakan sensor PIR, sensor LM35, arduino, LED, LCD, relay yang dihubungkan menggunakan kabel jamper.

2. Kurang stabilnya sensor suhu LM35 dalam membaca suhu suatu ruangan sehingga menyebabkan ke tidak cocokan antara suhu yang tampil di LCD dengan lampu LED.

3. Sensitivitas dari sensor PIR kurang maksimal sehingga menyebabkan kipas kadang berhenti berputar karena sensor PIR tidak mendeteksi bayangan.

\section{DAFTAR PUSTAKA}

Andi Adriansyah dan Oka Hidayatma. (2013). Rancangan Bangun Prototipe Elevator Menggunakan Microcontroller Arduino ATMega 328. Jurnal. Teknik Elektro Universitas Mercu Buana.

Apriani Puji Lestari. (2015). Pengembangan Multimedia Pembelajaran Interaktif Gambar Teknik Berbasis Software Bantudi SMK Binawiata Sragen Kelas X Paket Keahlian
Tekni Otomasi Industri. Tugas Akhir. Teknik Elektro Universitas Negeri Yogyakarta.

Ari Wibowo. (2011). Pengaturan Kipas Berbasis Mikrokontroller Dengan Menggunakan Sensor Suhu. Tugas Akhir. Teknik Elektro Universitas Negeri Semarang.

Eka Desyantoro. (2015). Sistem Pengendali Peralatan Elektronik Dalam Rumah Secara Otomatis Menggunakan Sensor PIR, Sensor LM35 dan Sensor LDR. Jurnal. Teknik Sistem Komputer Universitas Diponegoro.

IPCC. (2007). Climate Change 2007 Synthesis Report. Intergovernmental Panel on Climate Change [Core Writing Team IPCC].

IPCC. (2014). Summary for Policymakers. Climate Change 2014: Impacts, Adaptation and Vulnerability - Contributions of the Working Group II to the Fifth Assessment Report.

Joni Parhan dan Rahmat Rasyid. (2018). Rancangan Bangun Sistem Kontrol Kipas Angin dan Lampu Otomatis di Dalam Ruangan Berbasis Arduino Uno R3 Menggunakan Multi Sensor. Jurnal. Jurusan Fisika Universitas Andalas.

Kementrian Perencanaan Pembangunan Nasional/Badan Perencanaan Pembangunan Nasional (Bappenas). (2014). Rencana Aksi Nasional Adaptasi Perubahan Iklim.

Lisinius Suryadi dkk. (2015). Perancangan Sistem Kontrol Kipas Angin Otomatis Menggunakan Sensor Suhu LM35 Berbasis Mikrokontroller ATMega16. Jurnal. Teknik Informatika STMIK Widya Dharma.

Yadi Suryadi, (2017). Identifikasi Perubahan Suhu dan Curah Hujan Serta Proyeksinya di Kota Semarang. Jurnal. School Of Postgraduate Studies, Diponegoro University. 